\title{
Age-adjusted association of homologous recombination genes with ovarian cancer using clinical exomes as controls
}

Kevin J. Arvai ${ }^{1 *}$ D, Maegan E. Roberts ${ }^{1}$, Rebecca I. Torene ${ }^{1}$, Lisa R. Susswein ${ }^{1}$, Megan L. Marshall' Zhancheng Zhang ${ }^{1}$, Natalie J. Carter ${ }^{1}$, Lauren Yackowski ${ }^{1}$, Erica S. Rinella ${ }^{1}$, Rachel T. Klein ${ }^{2}$, Kathleen S. Hruska ${ }^{1}$ and Kyle Retterer ${ }^{1}$

\begin{abstract}
Background: Genes in the homologous recombination pathway have shown varying results in the literature regarding ovarian cancer (OC) association. Recent case-control studies have used allele counts alone to quantify genetic associations with cancer.

Methods: A retrospective case-control study was performed on 6,182 women with OC referred for hereditary cancer multi-gene panel testing (cases) and 4,690 mothers from trios who were referred for whole-exome sequencing (controls). We present age-adjusted odds ratios $\left(\mathrm{OR}_{\mathrm{Adj}}\right)$ to determine association of $\mathrm{OC}$ with pathogenic variants (PVs) in homologous recombination genes.

Results: Significant associations with OC were observed in BRCA1, BRCA2, RAD51C and RAD51D. Other homologous recombination genes, BARD1, NBN, and PALB2, were not significantly associated with OC. ATM and CHEK2 were only significantly associated with $\mathrm{OC}$ by crude odds ratio $\left(\mathrm{OR}_{\text {crude }}\right)$ or by $O \mathrm{R}_{\mathrm{Adj}}$, respectively. However, there was no significant difference between $O R_{C r u d e}$ and $O R_{\text {Adj }}$ for these two genes. The significant association of PVs in $B R I P 1$ by $\mathrm{OR}_{\text {Crude }}(2.05, \mathrm{Cl}=1.11$ to $3.94, P=0.03)$ was not observed by $\mathrm{OR}_{\text {Adj }}(0.87, \mathrm{Cl}=0.41$ to $1.93, P=0.73)$. Interestingly, the confidence intervals of the two effect sizes were significantly different $(P=0.04)$.

Conclusion: The lack of association of PVs in BRIP1 with $O C$ by $O R_{\text {Adj }}$ is inconsistent with some previous literature and current management recommendations, highlighted by the significantly older age of OC onset for BRIP1 PV carriers compared to non-carriers. By reporting $O R_{\text {Adj, }}$ this study presents associations that reflect more informed genetic contributions to OC when compared to traditional count-based methods.
\end{abstract}

Keywords: Ovarian Cancer, BRIP1, Exome sequencing

\section{Background}

Next-generation sequencing (NGS) has enabled clinical laboratories to analyze simultaneously a growing number of genes. Clinical multi-gene hereditary ovarian cancer (OC) panels include genes that function in the same homologous recombination (HR) DNA repair pathway as BRCA1 and BRCA2, such as ATM, BARD1, BRIP1, CHEK2, NBN, PALB2, RAD51C, and RAD51D. These genes have been linked to hereditary ovarian cancer, but the extent to which some of these genes contribute to

\footnotetext{
* Correspondence: karvai@genedx.com

'GeneDx, 207 Perry Pkwy, Gaithersburg, MD, USA

Full list of author information is available at the end of the article
}

hereditary OC varies in the literature [1-7]. The identification of pathogenic or likely pathogenic variants $(\mathrm{PVs})$ in these genes with ambiguous associations leads to difficult patient management decisions for clinicians and patients alike.

Identifying an appropriate control group for genetic association studies is vital for accurate estimation of cancer risks. Before high-throughput NGS, researchers relied on collaboration by pooling multi-center genotype data to achieve a large enough sample size to detect significant genetic associations $[8,9]$. Recent association studies have drawn control data from the Exome Aggregation Consortium (ExAC), a public database which

(c) The Author(s). 2019 Open Access This article is distributed under the terms of the Creative Commons Attribution 4.0 International License (http://creativecommons.org/licenses/by/4.0/), which permits unrestricted use, distribution, and 
contains genotype information on over 60,000 individuals who have participated in genetic studies on conditions such as inflammatory bowel disease, heart disease, and schizophrenia [10-12]. The FLOSSIES database has also been used to perform genetic association studies specifically in women's cancer [13]. The advantage of such cohorts are the large, readily available number of genotyped individuals with diverse ancestries and varied clinical histories, but drawbacks include the lack of specific phenotypic information including age and cancer history of the participants.

Clinical laboratories are addressing this limitation by leveraging data from exome sequencing (ES) tests performed internally [14]. In our laboratory, ES can be performed on trios (child and both parents) to help identify variants contributing to rare Mendelian diseases. Healthy parents from these trios serve as a reliable control cohort for hereditary cancer studies considering the breadth of genotyping coverage and the adequate phenotypic information provided. We performed a casecontrol study with an internal control population and report age-adjusted ORs to clarify equivocal genetic associations in HR genes with OC.

\section{Methods}

\section{Cohort assembly}

Genotypic and phenotypic data were collected from women who underwent germline genetic testing at GeneDx (Gaithersburg, MD) between 2013 and 2018. The study was conducted in accordance with all guidelines set forth by the Western Institutional Review Board, Puyallup, WA (WIRB 20162523). Informed consent for genetic testing was obtained from all individuals undergoing testing, and WIRB waived authorization for use of de-identified aggregate data for both cases and controls. Individuals or institutions who opted out of this type of data use were excluded. Cases were women with OC referred for $B R C A 1 / 2$ alone or multi-gene hereditary cancer panel testing who did not also have a targeted test for a known familial variant. Controls were mothers from a subset of complete trios referred for ES due to a neurodevelopmental delay in the proband. These mothers all self-reported that they did not have a disorder with genetic etiology. Both case and control cohorts were limited to those over 18 years of age and those who self-reported as White/Caucasian. Women were excluded if they were missing age at diagnosis or age at testing or if they had more than one PV, including homozygous variants, in any of the cancer predisposition genes available on ordered panels (Additional file 1: Table S1). Of all individuals referred for multi-gene hereditary cancer panel testing, 9,688 women were diagnosed with OC, 6,182 of whom met inclusion criteria.
From the control cohort, there were 8,643 mothers of probands, of whom 4,690 satisfied the filtering criteria.

\section{Sequencing and variant calling}

Cases were sequenced and genotyped with targeted NGS panels and a clinical bioinformatics pipeline as previously described [15]. Controls were sequenced by clinical ES as previously described using either Agilent SureSelect Human All Exon v4 or Agilent Clinical Research Exome capture protocols (Agilent, Santa Clara, CA) [16]. Separate from clinical ES testing, control samples were jointly genotyped across the entire cohort following Genome Analysis Toolkit Best Practices using HaplotypeCaller (version 3.7.0) in GVCF mode followed by GenotypeGVCFs and variant quality score recalibration [17-19]. Single nucleotide variants with genotype quality less than 50 and insertions and deletions (indels) with genotype quality less than 99 were considered low confidence, and therefore not included in the analysis. Additionally, for all novel prospective PVs in controls, de-identified NGS alignment data were manually inspected to remove suspicious variants. Sequencing methods for cases and controls were evaluated for potential bias (Additional file 2: Additional Sequencing Methods and Table S2). Copy number variants were not evaluated as part of this study.

\section{Variant classification}

Analysis of genetic variants were limited to those located in the HR genes, ATM, BARD1, BRCA1, BRCA2, BRIP1, CHEK2, NBN, PALB2, RAD51C, and RAD51D. For cases, the pathogenic classification of each variant was reviewed according to internal protocol, which follows ACMG/AMP guidelines [20]. Exon-level deletions and duplications were not included in the PV count since detection of these copy-number variants from ES is more limited and variable than from panel testing. Pathogenic status of variants in controls were systematically classified using a rule-based algorithm (Fig. 1). Variants that were previously classified in cases were assigned the same classification. Novel variants in the controls were assigned ClinVar classifications or were manually classified when ClinVar classifications were not available or conflicting. ClinVar classifications were obtained from the variant call format file released September 5, 2017 [21]. The common founder pathogenic missense variants, CHEK2"I157T and CHEK2*S428F were excluded from both cases and controls. All PVs are listed in Additional file 3: Table S3.

\section{Statistical analysis}

A two-sample, independent $\mathrm{t}$-test was performed to compare the mean age between cases and controls. Genetic associations were estimated by ORs using Firth bias- 


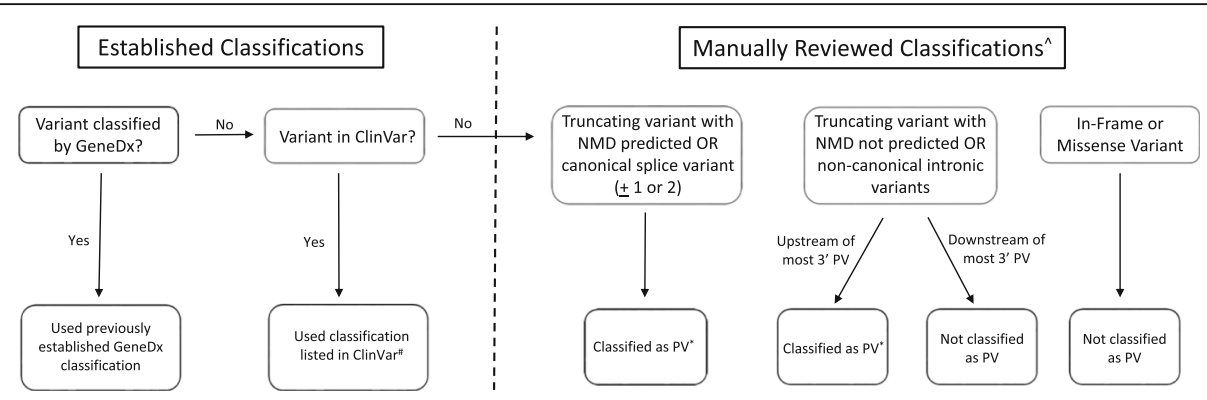

Fig. 1 Rule-Based Algorithm Used to Classify Variants. "No classification discrepancies were identified for variants falling into this category (not previously seen at GeneDx but in ClinVar). ${ }^{\wedge}$ Variants requiring manual review were not classified based on strict ACMG criteria as is done for variants that were clinically reported. Variants were classified as either a PV, which includes variants that would meet criteria for a pathogenic or likely pathogenic classification, or not a PV. Variants determined to be not a PV were not worked up further to determine if they would be classified as variant of uncertain significance, likely benign, or benign. ${ }^{*} \mathrm{NGS}$ data manually assessed to ensure variant was real. Default as real if it was determined that the variant in question could not be confidently called real or not real based on NGS data. NMD = nonsense mediated decay

corrected logistic regression [22]. Crude ORs (OR were generated by simple logistic regression using status of PV in a gene as the independent variable. Multivariable logistic regression was performed with PV status and patient age (diagnosis in cases, at time of testing in controls) as independent variables to generate $\mathrm{OR}_{\text {Adj }}$. Reported 95\% confidence intervals (CIs) were calculated using penalized profile likelihood. A z-test was performed to compare $\mathrm{OR}_{\text {Crude }}$ and $\mathrm{OR}_{\text {Adj }}$ for each gene (Additional file 4). The aggregate PV prevalence per-gene was compared to reported prevalence from Lilyquist et al. using Fisher's exact test [23]. To correct for multiple independent tests, a Benjamini-Hochberg false discovery rate (FDR) correction was applied and a corrected $p$-value significance threshold of 0.05 was used when considering genetic association results and results from Fisher's exact test. The t-test and ztests were two-sided and $P<0.05$ were considered significant. A sensitivity analysis was performed by reporting $\mathrm{OC}$ associations in a subset of women who were diagnosed with serous OC subtype (Additional file 5: Table S4). Finally, a power analysis was performed using a test of proportions to determine the statistical power of the study. Conditions of the test used the total cohort sizes, assumed a significance level of 0.05 , and a subjective, but realistic, assumption that rate of PVs in each cohort were 0.01 , and 0.005 , respectively. Statistical analyses were performed using the $\mathrm{R}$ programming language.

\section{Results}

\section{Cohort summary}

After filtering into final cohorts, the mean age (standard deviation) at OC diagnosis was significantly higher in cases than age at testing in controls (58.8 (13.4) versus 41.9 (9.4), $P<.05$, t-test). The median age at diagnosis of PV carriers in OC cases ranged from 53 years in BRCA1 to 67 years in BRIP1, while the median age of testing of PV carriers in controls ranged from 32.5 years in RAD51D to 46 years in BRIP1 (Table 1). There were 780
(12.6\%) OC cases who also had a breast cancer diagnosis. Across all genes, the observed aggregate PV prevalence in either the case or control cohort were not significantly different, respectively, from those reported by Lilyquist et al. ( $P=0.05$, Fisher's exact test). There were 588 women of the 6,182 cases who harbored PVs (9.5\%) while 98 of the 4,690 controls $(2.1 \%)$ harbored PVs (Table 1).

\section{Genetic associations}

Well-established OC susceptibility genes showed significant associations when measured by both $\mathrm{OR}_{\text {Crude }}$ and $\mathrm{OR}_{\text {Adj: }}$ BRCA1 $\left(\mathrm{OR}_{\text {Crude }}=38.46, \mathrm{CI}=17.03\right.$ to 115.32 , $P=1.03 \times 10^{-47} ; \mathrm{OR}_{\mathrm{Adj}}=47.80, \mathrm{CI}=20.76$ to 145.03 , $\left.P=1.87 \times 10^{-46}\right), B R C A 2\left(\mathrm{OR}_{\text {Crude }}=8.19, \mathrm{CI}=5.22\right.$ to $13.67, P=1.17 \times 10^{-28} ; \mathrm{OR}_{\mathrm{Adj}}=5.10, \mathrm{CI}=3.12$ to 8.83 , $\left.P=2.89 \times 10^{-12}\right), R A D 51 C\left(\mathrm{OR}_{\text {Crude }}=15.28, \mathrm{CI}=3.97\right.$ to 137.01, $P=6.09 \mathrm{x}^{-06} ; \mathrm{OR}_{\mathrm{Adj}}=12.09, \mathrm{CI}=2.78$ to 114.43 , $\left.P=7.85 \times 10^{-04}\right)$, and $\operatorname{RAD} 51 D\left(\mathrm{OR}_{\text {Crude }}=7.99, \mathrm{CI}=\right.$ 2.56 to $39.77, P=1.97 \times 10^{-04} ; \mathrm{OR}_{\mathrm{Adj}}=8.38, \mathrm{CI}=2.17$ to 47.23, $P=2.51 \times 10^{-03}$ ) (Table 1 ).

Some genes with no significant association with OC measured by $\mathrm{OR}_{\text {Crude }}$ consistently showed no significant association with $\mathrm{OC}$ as measured by $\mathrm{OR}_{\mathrm{Adj}}$, including BARD1 $\left(\mathrm{OR}_{\text {Crude }}=1.59, \mathrm{CI}=0.31\right.$ to $9.56, P=0.57$; $\mathrm{OR}_{\text {Adj }}=6.30, \mathrm{CI}=0.55$ to $\left.74.25, P=0.19\right), \quad N B N$ $\left(\mathrm{OR}_{\text {Crude }}=0.52, \mathrm{CI}=0.15\right.$ to $1.54, P=0.27 ; \mathrm{OR}_{\mathrm{Adj}}=0.45$, $\mathrm{CI}=0.10$ to $1.82, P=0.33)$, and PALB2 $\left(\mathrm{OR}_{\text {Crude }}=2.06\right.$, $\mathrm{CI}=0.90$ to $5.19, P=0.11 ; \mathrm{OR}_{\mathrm{Adj}}=1.78, \mathrm{CI}=0.61$ to $5.59, \mathrm{P}=0.33)$.

ATM $\left(\mathrm{OR}_{\text {Crude }}=2.01, \mathrm{CI}=1.15\right.$ to $3.64, P=0.03$; $\mathrm{OR}_{\text {Adj }}=1.72, \mathrm{CI}=0.89$ to $\left.3.44, P=0.18\right)$ and $B R I P 1$ $\left(\mathrm{OR}_{\text {Crude }}=2.05, \mathrm{CI}=1.11\right.$ to $3.94, \mathrm{P}=0.03 ; \mathrm{OR}_{\mathrm{Adj}}=0.87$, $\mathrm{CI}=0.41$ to $1.93, P=0.73$ ) were significantly associated with $\mathrm{OC}$ by $\mathrm{OR}_{\text {Crude }}$ but were not significantly associated with $\mathrm{OC}$ by $\mathrm{OR}_{\text {Adj }}$. Conversely, CHEK2 $\left(\mathrm{OR}_{\text {Crude }}=\right.$ $1.62, \mathrm{CI}=1.00$ to $2.69, P=0.07 ; \mathrm{OR}_{\mathrm{Adj}}=2.64, \mathrm{CI}=1.48$ 
Table 1 Associations of ovarian cancer with pathogenic variants in homologous recombination genes among self-reported white women

\begin{tabular}{|c|c|c|c|c|c|c|c|c|}
\hline Gene & $\begin{array}{l}\text { Median Age of } \\
\text { PV Carriers } \\
\left.\text { (Cases }^{a} \text {, Controls }{ }^{b}\right)\end{array}$ & $\begin{array}{l}\text { Crude Odds } \\
\text { Ratio (Cl) }\end{array}$ & $\begin{array}{l}p \text {-value, } \\
\text { Crude }^{c}\end{array}$ & $\begin{array}{l}\text { Adjusted Odds } \\
\text { Ratio (CI) }\end{array}$ & $\begin{array}{l}p \text {-value, } \\
\text { Adjusted }^{c}\end{array}$ & $\begin{array}{l}\text { Case Carriers, } \\
\text { No. (Non-Carriers) }\end{array}$ & $\begin{array}{l}\text { Control Carriers, } \\
\text { No. (Non-Carriers) }\end{array}$ & $\begin{array}{l}p \text {-value, } \\
z \text {-test }{ }^{e}\end{array}$ \\
\hline ATM & $55.0,47.0$ & 2.01. (1.15 to 3.64$)$ & 0.03 & 1.72 (0.89 to 3.44$)$ & 0.18 & 35 (4724) & 17 (4673) & 0.35 \\
\hline BARD1 & $60.0,34.5$ & 1.59 (0.31 to 9.56$)$ & 0.57 & 6.30 (0.55 to 74.25$)$ & 0.19 & $3(4122)$ & $2(4688)$ & 0.80 \\
\hline$B R C A 1$ & $53.0,37.0$ & 38.46 (17.03 to 115.32$)$ & $1.03 \times 10^{-47}$ & 47.80 (20.76 to 145.03$)$ & $1.87 \times 10^{-46}$ & 219 (5944) & $4(4686)$ & 0.60 \\
\hline BRCA2 & $63.0,40.0$ & 8.19 (5.22 to 13.67$)$ & $1.17 \times 10^{-28}$ & 5.10 (3.12 to 8.83 ) & $2.89 \times 10^{-12}$ & 193 (5969) & $18(4672)$ & 0.14 \\
\hline BRIP1 & $67.0,46.0$ & 2.05 (1.11 to 3.94$)$ & 0.03 & 0.87 (0.41 to 1.93$)$ & 0.73 & $30(4805)$ & $14(4676)$ & 0.04 \\
\hline CHEK2 & $52.0,42.0$ & 1.62 (1.00 to 2.69$)$ & 0.07 & 2.64 (1.48 to 4.79$)$ & $2.36 \times 10^{-3}$ & 45 (4923) & $24(4287)$ & 0.79 \\
\hline NBN & $64.5,37.0$ & 0.52 (0.15 to 1.54$)$ & 0.27 & 0.45 (0.10 to 1.82$)$ & 0.33 & $4(4232)$ & $9(4681)$ & 0.46 \\
\hline PALB2 & $62.0,39.0$ & 2.06 (0.90 to 5.19$)$ & 0.11 & $1.78(0.61$ to 5.59$)$ & 0.33 & $16(5004)$ & $7(4683)$ & 0.50 \\
\hline RAD51C & $61.0,39.0$ & 15.28 (3.97 to 137.01$)$ & $6.29 \times 10^{-06}$ & 12.09 (2.78 to 114.43$)$ & $7.85 \times 10^{-04}$ & $23(4809)$ & $1(4689)$ & 0.34 \\
\hline RAD51D & $60.0,32.5$ & 7.99 (2.56 to 39.77$)$ & $1.97 \times 10^{-04}$ & 8.38 (2.17 to 47.23 ) & $2.51 \times 10^{-03}$ & $20(4809)$ & $2(4688)$ & 0.44 \\
\hline
\end{tabular}

${ }^{\mathrm{a} A g e}$ (in years) at time of ovarian cancer diagnosis

${ }^{\mathrm{b}}$ Age (in years) at time of testing

'Corrected for False Discovery Rate

${ }^{\mathrm{d}}$ All genes were not tested for every sample

e Comparing crude odds ratio to adjusted odds ratio

Cl Confidence Interval, No. Number

to $4.79, P=2.36 \times 10^{-3}$ ) was not significantly associated with $\mathrm{OC}$ by $\mathrm{OR}_{\text {Crude }}$ but was significantly associated with OC by $\mathrm{OR}_{\text {Adj. }}$.

\section{Power analysis and effect size comparison}

The power analysis revealed that the study can detect a difference in proportions from 0.01 to 0.005 with $85.9 \%$ power. The per-gene comparison of effect sizes was not significantly different for the majority of the genes evaluated. The single exception was BRIP1, for which OR $\mathrm{OR}_{\mathrm{Adj}}$ was significantly lower than $\mathrm{OR}_{\text {Crude }}$ (z-test, $P=0.04$ ) (Table 1).

\section{Discussion}

Our approach is supported by the agreement of $\mathrm{OR}_{\text {Crude }}$ and $\mathrm{OR}_{\text {Adj }}$ with previously reported ORs for BRCA1, $B R C A 2, R A D 51 C$, and $R A D 51 D$, genes with clearly established OC associations. The other HR pathway genes have been reported with conflicting evidence for association with OC $[10,14,23-25]$. Association of PVs in each these genes with $\mathrm{OC}$ are in agreement with at least one of these studies by either $\mathrm{OR}_{\text {Crude }}$ or $\mathrm{OR}_{\mathrm{Adj}}$. While this validates that our methodology is comparable, it also highlights the disparity of concordance among these studies.

To check for potential ascertainment bias, PV prevalence in cases and controls was compared to those previously reported by Lilyquist et al. [26] Given the similar ascertainment of cases and robustness of the estimates from the ExAC non-Finnish European control population, this data serves as a germane baseline for comparison. The prevalence of PV was not significantly different in any gene (Additional file 6: Table S5). Small differences in PV counts due to differences in variant classification between studies can have a significant impact on effect size, especially for genes where PVs are rare. For example, Weber-Lassalle et al. reported 9 of 7 , 325 (0.12\%) European PV carriers from the FLOSSIES database; however, our variant classification system would have reported 14 of 7,325 (0.19\%), on the basis of including 5 European carriers of BRIP1 c.139C $>$ A (ClinVar: SCV000210833.12) (Fig. 1) [13].

Genes in which PVs are rare in one cohort (four or less PVs), BARD1, BRCA1, NBN, RAD51C and RAD51D, result in wide confidence intervals for the ORs. For example, $R A D 51 C$ appears to confer greater risk than $B R C A 2$, a gene whose association with $\mathrm{OC}$ has been well-established. However, with the exception of CHEK2, confidence intervals for ORs in all HR genes overlapped with those previously published, indicating the true effect size falls somewhere in the overlapping range [10]. Results from the power analysis can be interpreted that genes with moderate effect sizes are adequately powered to detect significant association but the result also supports the argument in favor of performing studies on genotyped cohorts large enough to sufficiently detect genetic associations in genes where PVs rare and the effect sizes are small.

No significant association with $\mathrm{OC}$ were consistently observed with PVs in BARD1, NBN, and PALB2. The reported low frequency of PVs in BARD1, similar to other studies, will require still larger sample sizes to detect a significant effect $[10,23,24]$. Association of $N B N$ with $\mathrm{OC}$ is the low to moderate risk HR pathway gene with the most concordant results. It is widely regarded as not significantly associated with $\mathrm{OC}$, with the exception of 
Lilyquist, et al. who reported that its association was "marginally significant" [23]. Additionally, Lilyquist et al. initially reported a significant association of PALB2 with $\mathrm{OC}$, but the association was lost upon removal of women with a personal or family history of breast cancer [23]. We also report no significant association of PALB2 with OC.

Multiple studies have reported $A T M$ as a moderate risk OC gene [14, 23]. The observed significance by $\mathrm{OR}_{\text {Crude }}$ is concordant with these results. In controls, ATM PV carriers had the highest median age ( 47 years, time of testing) of any HR pathway genes. Given that PVs in ATM were only moderately associated with OC by $\mathrm{OR}_{\text {Crude, }}$, the median age of PV carriers was high enough compared to the median age of non-carriers to decrease the $\mathrm{OR}_{\text {Adj }}$ below the significance threshold. Notably, an insignificant z-test result indicates that the true effect size is likely to overlap the two reported CIs. The presence of undiagnosed cancer patients in the control cohort could falsely lower the calculated ORs, a similar effect was previously described in a study which used the ExAC controls with cancer samples included [10].

A well-known breast cancer risk gene, CHEK2, has been consistently reported to have no significant association with OC $[10,14,23]$. Similar to reported associations from $A T M$, the observed significance by $\mathrm{OR}_{\text {Crude }}$ is concordant with previously reported associations. In contrast, however, CHEK2 PV carriers in cases had the lowest median age ( 52 years, time of OC diagnosis) of any of the HR pathway genes, which increased the $\mathrm{OR}_{\mathrm{Adj}}$ enough to reach the level of significant association with OC. Again, similar to ATM, the z-test comparing the two effect sizes was insignificant, indicating that the true effect size is likely in the overlapping range of the CIs (Table 1). When limiting cases to women with serous OC pathology, association of OC with PVs in CHEK2 disappears and the median age of $\mathrm{OC}$ diagnosis in PV carriers increases from 52 years to 63.5 years (Additional file 5: Table S4). None of the 12 CHEK2 PV carriers with serous OC subtype were also diagnosed with breast cancer (not shown), suggesting that the significant $\mathrm{OR}_{\mathrm{Adj}}$ result from the larger case cohort was a direct effect from the bias introduced by the younger CHEK2 PV carriers who were also diagnosed with breast cancer.

Multiple publications have concluded that BRIP1 is significantly associated with OC $[10,13,23,24]$. While $\mathrm{OR}_{\text {Crude }}$ in BRIP1 was significantly associated with OC, the $\mathrm{OR}_{\text {Adj }}$ showed no $\mathrm{OC}$ association. The significantly decreased effect size in BRIP1 can be attributed to PV carriers displaying the oldest median age at time of OC diagnosis and the second oldest median age at time of testing among all of the genes (67y case PV carriers, 46y control PV carriers; Table). Advanced age of PV carriers in BRIP1 is not a novel observation [10, 13, 23, 24]. BRIP1 was the only gene in which $\mathrm{OR}_{\mathrm{Adj}}$ was significantly different than $\mathrm{OR}_{\text {Crude, }}$ which, given PV carriers are older compared to non-carriers, suggests that BRIP1 PV carriers are more likely to be diagnosed with lateonset OC. Recent updates to National Comprehensive Cancer Network ${ }^{\circ}$ (NCCN) guidelines for BRIP1 PV carriers include consideration of risk-reducing salpingooophorectomy at 45-50 years of age [26]. The consistently reported older age at time of diagnosis and the observed lack of association by $\mathrm{OR}_{\mathrm{Adj}}$ suggests caution before surgical intervention and the need for further studies of larger cohorts of older controls, as previously recommended [27].

A recent study reported no significant association of BRIP1 with OC, but our results reveal a clinically relevant factor that offers insight which may have contributed to the observed lack of association. Age (mean [SD]) at time of OC diagnosis in cases (55.7y [14.1]) and age at time of testing in controls (39.7y [14.7]) were both younger than our cohorts, which could lead to undercounting BRIP1 PV carriers. Finally, it has been suggested that BRIP1's OC association may be restricted to high-grade serous epithelial ovarian cancer, but when cases were restricted to women diagnosed with highgrade serous $\mathrm{OC}$ histologic subtype, the $\mathrm{OC}$ association was consistent (Additional file 5: Table S4) [7].

By presenting $\mathrm{OR}_{\text {Adj }}$ in addition to $\mathrm{OR}_{\text {Crude }}$ this study allows for comparison of the two effect sizes. This comparison provides insight into the age difference between PV carriers and non-carriers and enables inference of early/late onset OC. Genes with PV carriers who are older than non-carriers demonstrate decreased $\mathrm{OR}_{\mathrm{Adj}}$ compared to $\mathrm{OR}_{\text {Crude }}$ and conversely, genes with PV carriers who are younger than non-carriers have increased $\mathrm{OR}_{\text {Adj }}$ compared to $\mathrm{OR}_{\text {Crude. }}$ Comparing the two effect sizes for each gene using a z-test revealed that controlling for age did not significantly change the OR, except in BRIP1. A significant $\mathrm{z}$-test result suggests that BRIP1 PV carriers are more likely to be diagnosed with lateonset OC (Table 1).

As a referral laboratory, clinical information was limited to that provided by ordering providers with submitted samples. With ES, the referrals are not routinely submitted for cancer-related testing and, therefore, cancer history may not have been included in the clinical histories by the ordering physician. In addition, because the mean age of controls was lower than the mean age of OC diagnosis, it cannot be ruled out that some of these women will ultimately be diagnosed with OC. The OC referral cases could be biased toward a higher risk than the general ovarian cancer population. Variant detection sensitivity filters for controls were conservatively 
chosen which may lead to under-reporting of PVs and thus overestimation of ORs. Another source of possible under-reporting of PVs in controls is due to the incomplete gene coverage in controls, although the minor difference would have negligible effect (Additional file 2: Additional Sequencing Methods and Table S2). Copy number variants would have likely contributed a small number of PVs to cases and controls. But since this type of variant was not evaluated it acts as a source of bias toward under-reporting PVs. As not all PVs in controls were orthogonally confirmed as they were in cases, it is possible that a small number of control PVs were sequencing artifacts. Targeted BRCA1 and BRCA2 testing tends to have a lower positive yield compared to panel testing with other HR genes, as previously described [28]. The overall pathogenic variant rate in OC $(9.5 \%)$ is lower than published rates from other studies $[10,23]$. This can be attributed 873 women in the case cohort who underwent testing for BRCA1 and/or BRCA2 only.

\section{Conclusions}

We present age-adjusted genetic associations for PVs in HR genes with OC, leveraging an internal control cohort of women who self-report as White/Caucasian. Our study design and analysis provide more informed estimates of association compared to recently published OC associations by reporting both $\mathrm{OR}_{\text {Crude }}$ and $\mathrm{OR}_{\mathrm{Adj}}$. These results are most relevant for BRIP1 PV carriers, as our findings for this gene are disparate from recent literature and conflict with current management guidelines.

\section{Additional files}

Additional file 1: Genes on GeneDx inherited cancer panels. (DOCX $13 \mathrm{~kb}$ )

Additional file 2: Additional sequencing methods and statistics. Details of GeneDx sequencing QC for comparison between cases and controls. (DOCX $13 \mathrm{~kb}$ )

Additional file 3: List of all pathogenic variants. The gene, cDNA, and protein change for each variant found in this study. (DOCX $57 \mathrm{~kb}$ )

Additional file 4: Calculation of the z-Statistic. The formula used to determine if crude odds ratios were significantly different than adjusted odds ratios. (DOCX $12 \mathrm{~kb}$ )

Additional file 5: Serous-subtype ovarian cancer sensitivity analysis. Results when limited to women with serous-subtype ovarian cancer. (DOCX $14 \mathrm{~kb})$

Additional file 6: Comparison of pathogenic variant prevalence with Lilyquist et al. Results from Fisher's Exact Test comparing prevalence of pathogenic variants in homologous recombination genes to Lilyquist et al. (DOCX $14 \mathrm{~kb})$

\section{Abbreviations}

ACMG: American college of medical genetics; AMP: Association for Molecular Pathology; Cl: Confidence interval; ClinVar: Public database of reports of human variation; ES: Exome sequencing; ExAC: Exome aggregation consortium; FDR: False discovery rate; FLOSSIES: A sequencing database of women who are cancer free and over age 70; HR: Homologous recombination; NCCN: National

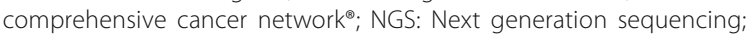

OC: Ovarian cancer; OR: Odds ratio; OR Adj: Adjusted odds ratio; OR crude $_{\text {: Crude }}$ odds ratio; PV: Pathogenic variant

\section{Acknowledgements}

Not applicable

\section{Author's contributions}

All authors participated in some part of the study. KA, KR, RT, and LS designed the study. KA drafted the manuscript with contributions from MR, LS, RT, MM, $K R$, and ZZ. KA, RT, LS, MR, and MM performed data processing of the case cohort. ZZ performed data processing of the control cohort. KA, MR, LS, MM, LY, and $N C$ reviewed relevant literature. KA and RT performed statistical analyses. $\mathrm{MR}$ and $\mathrm{ER}$ manually reviewed variants. $\mathrm{KR}, \mathrm{KH}$, and RK provided supervision and critical review of the study. All authors read and approved the final manuscript.

\section{Funding}

This study was supported by GeneDx, Inc.

\section{Availability of data and materials}

The datasets generated and/or analysed during the current study are not publicly available due to patient privacy restrictions but are available from the corresponding author on reasonable request.

\section{Ethics approval and consent to participate}

The study was conducted in accordance with all guidelines set forth by the Western Institutional Review Board, Puyallup, WA (WIRB 20162523). Informed consent for genetic testing was obtained from all individuals undergoing testing, and WIRB waived authorization for use of de-identified aggregate data for both cases and controls.

\section{Consent for publication}

Not Applicable

\section{Competing interests}

The following individuals are employed by GeneDx, Inc., a wholly owned subsidiary of OPKO Health, Inc.: Arvai, Roberts, Torene, Susswein, Marshall, Zhang, Carter, Yackowski, Rinella, Hruska, and Retterer. In addition, Dr. Hruska and Mr. Retterer have stock in OPKO Health, Inc.to disclose. Rachel Klein has stock options and employment with MyGeneTeam/OPKO Health, and indirect contractual relationships with GeneDx/BioReference Laboratories.

\section{Author details}

${ }^{1}$ GeneDx, 207 Perry Pkwy, Gaithersburg, MD, USA. My Gene Team, Miami, Florida, USA

Received: 25 February 2019 Accepted: 3 July 2019

Published online: 15 July 2019

\section{References}

1. Casadei S, Norquist BM, Walsh T, Stray SM, Mandell JB, Lee MK, et al. Contribution to familial breast Cancer of inherited mutations in the BRCA2-interacting protein PALB2. Cancer Res. 2011;3958:2010.

2. Loveday C, Turnbull C, Ramsay E, Hughes D, Ruark E, Frankum JR, et al. Germline mutations in RAD51D confer susceptibility to ovarian cancer. Nat Genet. 2011;43(9):879-82.

3. Loveday C, Turnbull C, Ruark E, Xicola RMM, Ramsay E, Hughes D, et al. Germline RAD51C mutations confer susceptibility to ovarian cancer. Nat Genet. 2012;44(5):475-6; author reply 476.

4. Pennington KP, Walsh T, Harrell MI, Lee MK, Pennil CC, Rendi MH, et al. Germline and somatic mutations in homologous recombination genes predict platinum response and survival in ovarian, fallopian tube, and peritoneal carcinomas. Clin Cancer Res An Off J Am Assoc Cancer Res. 2014; 20(3):764-75.

5. Meindl A, Hellebrand H, Wiek C, Erven V, Wappenschmidt B, Niederacher D, et al. Germline mutations in breast and ovarian cancer pedigrees establish RAD51C as a human cancer susceptibility gene. Nat Genet. 2010;42(5):410-4.

6. Rafnar T, Gudbjartsson DF, Sulem P, Jonasdottir A, Sigurdsson A, Jonasdottir $A$, et al. Mutations in BRIP1 confer high risk of ovarian cancer. Nat Genet. 2011;43(11):1104-7. 
7. Walsh T, Casadei S, Lee MK, Pennil CC, Nord AS, Thornton AM, et al. Mutations in 12 genes for inherited ovarian, fallopian tube, and peritoneal carcinoma identified by massively parallel sequencing. Proc Natl Acad Sci U S A. 2011:108(44):18032-7.

8. Schildkraut JM, Risch N, Thompson WD. Evaluating genetic association among ovarian, breast, and endometrial cancer: evidence for a breast/ ovarian cancer relationship. Am J Hum Genet. 1989;45(4):521-9 Available from: http://www.ncbi.n/m.nih.gov/pubmed/2491011. Cited 2018 Jun 26.

9. Consortium CBCC-C. CHEK2*1100delC and susceptibility to breast cancer: a collaborative analysis involving 10,860 breast cancer cases and 9,065 controls from 10 studies. Am J Hum Genet. 2004;74(6):1175-82 Available from: https://linkinghub.elsevier.com/retrieve/pii/S0002929707627049. 30/ 04/2004. Cited 2018 Jul 23.

10. Norquist BM, Harrell MI, Brady MF, Walsh T, Lee MK, Gulsuner S, et al. Inherited mutations in women with ovarian carcinoma. JAMA Oncol. 2016;2(4):482-90.

11. Couch FJ, Shimelis H, Hu C, Hart SN, Polley EC, Na J, et al. Associations between cancer predisposition testing panel genes and breast cancer. JAMA Oncol [Internet. 2017;3(9):1190-6. https:/doi.org/10.1001/jamaoncol.2017.0424.

12. Castéra L, Harter V, Muller E, Krieger S, Goardon N, Ricou A, et al. Landscape of pathogenic variations in a panel of 34 genes and cancer risk estimation from 5131 HBOC families. Genet Med. 2018;1 Available from: http://www. nature.com/articles/s41436-018-0005-9. Cited 2018 Aug 31.

13. Weber-Lassalle N, Hauke J, Ramser J, Richters L, Groß E, Blümcke B, et al. BRIP1 loss-of-function mutations confer high risk for familial ovarian cancer, but not familial breast cancer. Breast Cancer Res. 2018;20(1):7 Available from: http://www.ncbi.nlm.nih.gov/pubmed/29368626. Cited 2018 Jul 19.

14. Lu HM, Li S, Black MH, Lee S, Hoiness R, Wu S, et al. Association of Breast and Ovarian Cancers with predisposition genes identified by large-scale sequencing. JAMA Oncol. 2019;5(1):51-7 Available from: https://doi.org/10.1 001/jamaoncol.2018.2956

15. Roberts ME, Jackson SA, Susswein LR, Zeinomar N, Ma X, Marshall ML, et al. MSH6 and PMS2 germ-line pathogenic variants implicated in Lynch syndrome are associated with breast cancer. Genet Med. 2018;20(10):116774 Available from: http://www.nature.com/doifinder/10.1038/gim.2017.254. Cited 2018 Feb 1.

16. Retterer K, Juusola J, Cho MT, Vitazka P, Millan F, Gibellini F, et al. Clinical application of whole-exome sequencing across clinical indications. Genet Med. 2016;18(7):696-704 Available from: http://www.nature.com/articles/ gim2015148. Cited 2018 Jul 30.

17. Depristo MA, Banks E, Poplin R, Garimella KV, Maguire JR, Hartl C, et al. A framework for variation discovery and genotyping using next-generation DNA sequencing data. Nat Genet. 2011;43(5):491-501 Available from: http:// www.ncbi.nlm.nih.gov/pubmed/21478889. Cited 2018 Jul 30.

18. Van der Auwera GA, Carneiro MO, Hartl C, Poplin R, del Angel G, LevyMoonshine A, et al. From fastQ data to high-confidence variant calls: the genome analysis toolkit best practices pipeline. Curr Protoc Bioinformatics. 2013;43(SUPL.43):11.10.1-33 Available from: http://www.ncbi.nlm.nih.gov/ pubmed/25431634. Cited 2018 Jul 30

19. Poplin R, Ruano-Rubio V, DePristo MA, Fennell TJ, Carneiro MO, Van der Auwera GA, et al. Scaling accurate genetic variant discovery to tens of thousands of samples. BioRxiv. 2017;201178 Available from: https://www. biorxiv.org/content/early/2017/11/14/201178.1. Cited 2018 Jan 29.

20. Richards S, Aziz N, Bale S, Bick D, Das S, Gastier-Foster J, et al. Standards and guidelines for the interpretation of sequence variants: a joint consensus recommendation of the American college of medical genetics and genomic and the association for molecular pathology. Genet Med. 2015;17(5):405-24 Available from: https://www.acmg.net/docs/standards_guidelines_for_the_ interpretation_of_sequence_variants.pdf. Cited 2018 Apr 5.

21. Landrum MJ, Lee JM, Benson M, Brown GR, Chao C, Chitipiralla S, et al. ClinVar: improving access to variant interpretations and supporting evidence. Nucleic Acids Res. 2018;46(D1):D1062-7 Available from: http:// www.ncbi.nlm.nih.gov/pubmed/29165669. Cited 2018 Apr 5.

22. Firth D. Bias Reduction of Maximum Likelihood Estimates. Biometrika. 1993; 80(1):27-38 Author ( s ): David Firth Published by : Biometrika Trust Stable URL: http://www.jstor.org/stable/2336755.

23. Lilyquist J, LaDuca H, Polley E, Davis BT, Shimelis H, Hu C, et al. Frequency of mutations in a large series of clinically ascertained ovarian cancer cases tested on multi-gene panels compared to reference controls. Gynecol Oncol. 2017;147(2):375-80 Available from: http://www.ncbi.n/m.nih.gov/ pubmed/28888541. Cited 2018 Jan 16
24. Ramus SJ, Song H, Dicks E, Tyrer JP, Rosenthal AN, Intermaggio MP, et al. Germline mutations in the BRIP1, BARD1, PALB2, and NBN genes in women with ovarian cancer. J Natl Cancer Inst. 2015;107(11) Available from: http:// www.ncbi.nlm.nih.gov/pubmed/26315354. Cited 2018 Jun 27.

25. Southey MC, Goldgar DE, Winqvist R, Pylkäs K, Couch F, Tischkowitz M, et al. PALB2, CHEK2 and ATM rare variants and cancer risk: data from COGS. J Med Genet. 2016;53(12):800-11.

26. National Comprehensive Cancer Network. Genetic/Familial High-Risk Assessment: Breast and Ovarian (Version 1.2017). 2017. Version 1.

27. Balmaña J, Domchek SM. BRIP1 as an ovarian cancer susceptibility gene: ready for the clinic? J Natl Cancer Inst. 2015;107(11):djv262 Available from: https://academic.oup.com/jnci/article-lookup/doi/10.1093/jnci/djv262. Cited 2018 Jul 2.

28. Carter NJ, Marshall ML, Susswein LR, Zorn KK, Hiraki S, Arvai KJ, et al. Germline pathogenic variants identified in women with ovarian tumors. Gynecol Oncol. 2018;151(3):481-8 Available from: https://doi.org/10.1 016/j.ygyno.2018.09.030

\section{Publisher's Note}

Springer Nature remains neutral with regard to jurisdictional claims in published maps and institutional affiliations.
Ready to submit your research? Choose BMC and benefit from:

- fast, convenient online submission

- thorough peer review by experienced researchers in your field

- rapid publication on acceptance

- support for research data, including large and complex data types

- gold Open Access which fosters wider collaboration and increased citations

- maximum visibility for your research: over $100 \mathrm{M}$ website views per year

At $\mathrm{BMC}$, research is always in progress.

Learn more biomedcentral.com/submissions 